\title{
Predictors of Length of Hospital Stay After Acute Myocardial Infarction in Japan
}

\author{
Kunihiro Kinjo, MD; Hiroshi Sato, MD; Daisaku Nakatani, MD; Hiroya Mizuno, MD; \\ Masahiko Shimizu, MD; Eiji Hishida, MD; Akira Ezumi, MD*; Shiro Hoshida, MD**; \\ Yukihiro Koretsune, $\mathrm{MD}^{\dagger}$; Masatsugu Hori, MD; \\ on Behalf of the Osaka Acute Coronary Insufficiency Study (OACIS) Group
}

\begin{abstract}
Background In Western countries, the length of hospital stay after acute myocardial infarction (AMI) has decreased dramatically during the past 3 decades and is now approximately 1 week. However, epidemiological data concerning the length of hospital stay, its predictors and trends based on a large-scale sample are still limited in Japan.

Methods and Results The study group comprised 4,113 surviving AMI patients who were enrolled in the Osaka Acute Coronary Insufficiency Study from April 1998 to March 2003. The mean length of hospital stay was 31.2 days. Clinical factors (patient characteristics, severity of infarction, therapy, and in-hospital complications) only explained $26 \%$ of the variation in hospital stay. The mean hospital stay was significantly longer in 1998 than in 2002. In 2002, occupational status and admission to a high-volume hospital were independent predictors of a shorter hospital stay, but this association was not observed in 1998.

Conclusions The hospital stay is still extremely long in Japan and clinical factors do not provide an explanation. The findings of the present study suggest that the hospital stay could be reduced in some patients with AMI, but randomized studies are needed to examine the feasibility of early discharge. (Circ J 2004; 68: 809-815)
\end{abstract}

Key Words: Acute myocardial infarction; Hospital stay; Japan

$I^{\prime}$ n Western countries, the mean length of hospital stay after acute myocardial infarction (AMI) has declined dramatically during the past 3 decades. In the 1970s, the length of hospital stay after AMI was generally 2-3 weeks, 1,2 although several randomized studies subsequently suggested the feasibility, safety, and cost effectiveness of discharging patients as early as 3-5 days after AMI ${ }^{3-5}$ Since then, the hospital stay after AMI has reduced to the current length of approximately 1 week in Western countries $^{6-9}$ In contrast, the length of stay after AMI remains at approximately 4 weeks in Japan, ${ }^{10-14}$ and epidemiological data concerning the length of hospital stay after AMI, its predictors and trends based on a large-scale sample are still limited. The Osaka Acute Coronary Insufficiency Study (OACIS), a large registry of patients with AMI, was established in 1998 to assess clinical variables, therapeutic procedures and clinical events, and can provide important data about recent trends in the pattern of care. The purpose of the present study was to examine the length of hospital stay after AMI as well as to identify the predictors and trends in hospital stay after AMI in Japan.

(Received March 25, 2004; revised manuscript received June 7, 2004; accepted June 15, 2004)

Department of Internal Medicine and Therapeutics, Osaka University Graduate School of Medicine, Suita, *Osaka Railway Hospital of West Japan Railway Company, **Yao Municipal Hospital, Yao and Osaka National Hospital, Osaka, Japan

Mailing address: Hiroshi Sato, MD, PhD, Department of Internal Medicine and Therapeutics, Osaka University Graduate School of Medicine, 2-2 Yamadaoka, Suita, Osaka 565-0871, Japan. E-mail: satoz@medone.med.osaka-u.ac.jp

\section{Methods}

\section{Purpose of the Registry}

A detailed description of the OACIS has been published elsewhere! ${ }^{15} 16$ The OACIS was a prospective, multicenter observational study involving 25 collaborating hospitals in the Osaka region of Japan. The registry was designed to collect uniform, prospective data on patients with AMI that could be used to assess clinical variables, therapeutic procedures and clinical events, and to collect DNA samples from the patients that could be used to investigate whether common genetic variations are involved in the pathogenesis of AMI. The study protocol was approved by each hospital's ethics committee.

\section{Definitions}

Diagnosis of AMI required the presence of 2 of the following 3 criteria: (1) a clinical history of central chest pressure, pain, or tightness lasting $30 \mathrm{~min}$ or more, (2) typical electrocardiographic changes (ie, ST segment elevation greater than $0.1 \mathrm{mV}$ in at least 1 standard or 2 precordial leads, ST segment depression greater than $0.1 \mathrm{mV}$ in at least 2 leads, abnormal $\mathrm{Q}$ waves, or $\mathrm{T}$ wave inversion in at least 2 leads), and (3) an increase of serum creatine kinase to 2-fold the upper limit of normal. All patients presenting within 1 week after the onset of AMI were registered prospectively, as soon as a diagnosis of AMI was made.

\section{Data Collection}

Research cardiologists and specialized research nurses recorded the data on the demographic variables, medical history, therapeutic procedures, and clinical events during the patient's hospital stay. Information was obtained from 
Table 1 Effect of Variables on Mean and Median Length of Hospital Stay

\begin{tabular}{|c|c|c|c|}
\hline \multirow{2}{*}{ Variable (\% of missing data) } & \multicolumn{2}{|c|}{ Mean (median) stay in days } & \multirow{2}{*}{$p$ value } \\
\hline & With variable & Without variable & \\
\hline \multicolumn{4}{|l|}{ Demographic factors } \\
\hline Age $\geq 70$ years $(0.0 \%)$ & $34.2(28)$ & $29.7(26)$ & $<0.001$ \\
\hline Female gender $(0.0 \%)$ & $35.0(28)$ & $29.8(26)$ & $<0.001$ \\
\hline Worker $(10.2 \%)$ & $28.3(25)$ & $33.9(28)$ & $<0.001$ \\
\hline \multicolumn{4}{|l|}{ Coronary risk factors } \\
\hline Obesity $(6.1 \%)$ & $30.0(26)$ & $31.7(27)$ & $<0.001$ \\
\hline Diabetes mellitus (2.8\%) & $33.4(28)$ & $30.1(26)$ & $<0.001$ \\
\hline Hypertension (3.1\%) & $31.9(27)$ & $30.2(27)$ & 0.115 \\
\hline Hyperlipidemia (4.5\%) & $29.9(26)$ & $32.0(27)$ & 0.039 \\
\hline Current smoking (3.2\%) & $29.1(26)$ & $33.1(28)$ & $<0.001$ \\
\hline \multicolumn{4}{|l|}{ Medical history } \\
\hline Prior myocardial infarction, $n=510(12.8 \%)$ & $35.4(28)$ & $30.1(26)$ & $<0.001$ \\
\hline Prior angina, $n=1,147(4.3 \%)$ & $32.0(27)$ & $30.2(26)$ & 0.008 \\
\hline Prior cerebrovascular disease (2.4\%) & $34.9(29)$ & $30.6(26)$ & $<0.001$ \\
\hline \multicolumn{4}{|l|}{ Infarct characteristics } \\
\hline Time from onset to presentation $<6 h(9.5 \%)$ & $29.4(26)$ & $31.2(27)$ & 0.004 \\
\hline Killip $\geq 2(4.5 \%)$ & $44.0(34)$ & $28.9(26)$ & $<0.001$ \\
\hline Systolic blood pressure <100 mmHg (1.9\%) & $38.0(29)$ & $29.9(26)$ & $<0.001$ \\
\hline Heart Rate $\geq 100$ beats $/ \min (4.0 \%)$ & $39.2(31)$ & $29.9(26)$ & $<0.001$ \\
\hline Anterior myocardial infarction (3.1\%) & $31.3(27)$ & $30.4(26)$ & 0.003 \\
\hline \multicolumn{4}{|l|}{ Procedures } \\
\hline \multicolumn{4}{|l|}{ Within 1 week of admission } \\
\hline Coronary angiography $(0.7 \%)$ & $30.6(26)$ & $36.7(29)$ & $<0.001$ \\
\hline$P C I(0.9 \%)$ & $30.6(27)$ & $32.8(27)$ & 0.162 \\
\hline Stenting (4.9\%) & $30.1(26)$ & $32.1(28)$ & $<0.001$ \\
\hline$C A B G(1.9 \%)$ & $46.1(37)$ & $30.5(26)$ & $<0.001$ \\
\hline Pulmonary artery catheterization (1.4\%) & $31.9(28)$ & $28.9(24)$ & $<0.001$ \\
\hline Temporary pacemaker $(14.0 \%)$ & $35.6(29)$ & $30.9(27)$ & 0.001 \\
\hline Percutaneous cardiopulmonary support (14.0\%) & $61.5(50)$ & $30.9(26)$ & $<0.001$ \\
\hline Intra-aortic balloon pumping (14.3\%) & $41.5(30)$ & $28.8(26)$ & $<0.001$ \\
\hline Mechanical ventilation (13.6\%) & $55.4(40)$ & $29.0(26)$ & $<0.001$ \\
\hline \multicolumn{4}{|l|}{ Before discharge } \\
\hline Coronary angiography $(2.4 \%)$ & $32.1(28)$ & $28.8(20)$ & $<0.001$ \\
\hline PCI $(10.9 \%)$ & $33.8(29)$ & $31.1(27)$ & $<0.001$ \\
\hline$C A B G(11.0 \%)$ & $55.8(56)$ & $30.9(28)$ & $<0.001$ \\
\hline Echocardiography (2.7\%) & $32.4(28)$ & $25.0(22)$ & $<0.001$ \\
\hline Exercise testing $(2.3 \%)$ & $29.8(27)$ & $32.4(26)$ & 0.097 \\
\hline Medications & & & \\
\hline Thrombolytics (1.6\%) & $34.7(29)$ & $30.5(26)$ & $<0.001$ \\
\hline Anticoagulants (10.7\%) & $31.1(27)$ & $29.5(26)$ & 0.047 \\
\hline Antiplatelet agents (10.6\%) & $30.4(26)$ & $43.8(36)$ & $<0.001$ \\
\hline ACE inhibitors $(1.1 \%)$ & $29.2(26)$ & $32.9(27)$ & 0.007 \\
\hline$\beta$-blockers (1.1\%) & $27.2(23)$ & $30.7(27)$ & 0.003 \\
\hline Nitrates $(1.1 \%)$ & $31.2(26)$ & $30.3(27)$ & 0.254 \\
\hline Ca channel blockers $(1.1 \%)$ & $33.5(26)$ & $30.5(27)$ & 0.701 \\
\hline Diuretics $(1.1 \%)$ & $35.1(28)$ & $28.2(26)$ & $<0.001$ \\
\hline Digitalis $(1.1 \%)$ & $39.0(31)$ & $30.3(26)$ & $<0.001$ \\
\hline Inotropic agents $(1.1 \%)$ & $38.2(30)$ & $27.7(25)$ & $<0.001$ \\
\hline In-hospital cardiac complications & $37.2(33)$ & $26.1(25)$ & $<0.001$ \\
\hline Congestive heart failure (1.1\%) & $42.5(34)$ & $28.5(25)$ & $<0.001$ \\
\hline Cardiogenic shock (1.2\%) & $51.8(39)$ & $30.2(26)$ & $<0.001$ \\
\hline Mechanical complications & $60.2(39)$ & $30.4(26)$ & $<0.001$ \\
\hline Ventricular septal perforation $(1.2 \%)$ & $127.7(71)$ & $30.6(27)$ & 0.003 \\
\hline Severe mitral regurgitation (1.2\%) & $42.2(40)$ & $30.8(26)$ & $<0.001$ \\
\hline Cardiac rupture $(1.2 \%)$ & $46.8(31)$ & $30.8(27)$ & 0.096 \\
\hline Reinfarction (0.7\%) & $43.3(34)$ & $30.6(26)$ & $<0.001$ \\
\hline Recurrent ischemia $(0.7 \%)$ & $45.1(34)$ & $30.4(26)$ & $<0.001$ \\
\hline Second-or third-degree AV block (0.7\%) & $33.6(28)$ & $30.7(26)$ & 0.007 \\
\hline Atrial fibrillation/flutter (0.7\%) & $40.1(31)$ & $29.7(26)$ & $<0.001$ \\
\hline Ventricular tachycardia/fibrillation (3.1\%) & $37.9(29)$ & $30.1(26)$ & $<0.001$ \\
\hline Thromboembolism $(3.1 \%)$ & $38.5(32)$ & $30.9(27)$ & 0.014 \\
\hline Stroke $(0.8 \%)$ & $55.1(42)$ & $30.7(26)$ & $<0.001$ \\
\hline Bleeding $(0.8 \%)$ & $50.1(34)$ & $30.3(26)$ & $<0.001$ \\
\hline Discharge day & & & \\
\hline Taian $(0.0 \%)$ & $32.0(28)$ & $30.9(26)$ & 0.005 \\
\hline Butsumetsu $(0.0 \%)$ & $31.8(27)$ & $31.1(26)$ & 0.812 \\
\hline Weekend $(0.0 \%)$ & $29.9(26)$ & $31.7(27)$ & 0.027 \\
\hline Hospital characteristics & & & \\
\hline Performance of PCI & & & \\
\hline$>200$ procedures/year $(0.0 \%)$ & $30.3(26)$ & $34.6(29)$ & $<0.001$ \\
\hline No. of beds $>200(0.0 \%)$ & $30.0(26)$ & $35.3(28)$ & $<0.001$ \\
\hline AMI case load $>50$ patients/year $(0.0 \%)$ & $30.2(26)$ & $33.9(29)$ & $<0.001$ \\
\hline
\end{tabular}

ACE, angiotensin-converting enzyme; AMI, acute myocardial infarction; $A V$, atrioventricular; $C A B G$, coronary artery bypass grafting; PCI, percutaneous coronary intervention. 


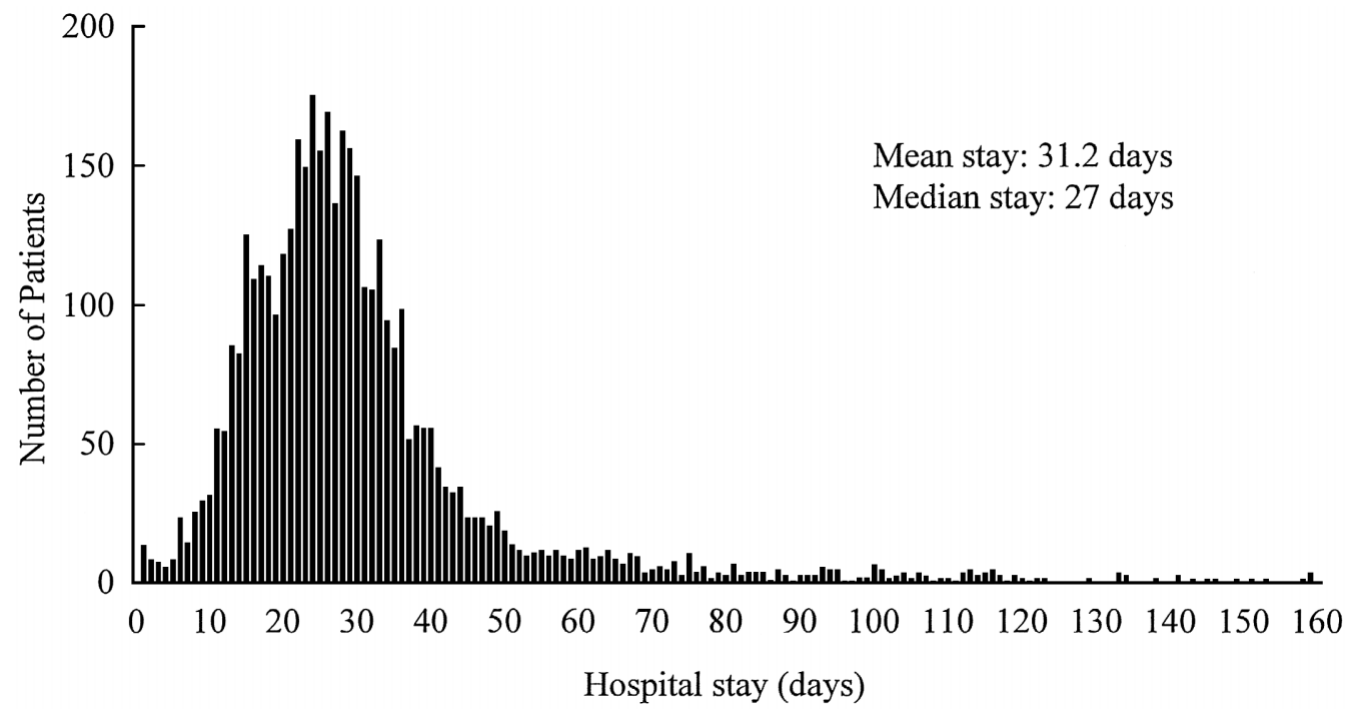

Fig 1. Distribution of the length of hospital stay for the total study population.

the hospital medical records and by direct interview with the patient, family members, and treating physician. After written informed consent to participate in the OACIS was obtained from the patient, all in-hospital data were transmitted to the data collection center located at the Department of Internal Medicine and Therapeutics in Osaka University Graduate School of Medicine for processing and analysis.

\section{Quality Control}

Before initiation of this study, a research cardiologist and specialized research nurse at each site received a training manual that explained how to complete the case report form, defined each variable, and provided examples of correct responses. Double-key entry was used by the data collection center to add each case report form to the database. Audits were performed electronically to detect out-ofrange variables, inconsistencies, errors, or omissions and then telephone contact was made with the study staff for resolution of any problems.

\section{Patients}

We registered 4,545 consecutive AMI patients in the OACIS from April 1998 to March 2003 and of these, 4,113 were discharged alive and were included in this study. The study population was $76.0 \%$ men and $24.0 \%$ women, with a mean age of 64.7 years.

\section{Variables}

As candidate factors affecting the length of hospital stay after AMI, we evaluated 59 variables including demographic factors, coronary risk factors, medical history, infarct characteristics, procedures, medications, in-hospital cardiac complications, the characteristics of the discharge day, and hospital characteristics (Table 1). It has been reported that Taian-Butsumetsu, a superstition relating to the traditional 6-day lunar calendar, influences the decision about hospital discharge in Japan, with the highest discharge rate on Taian (a lucky day) and the lowest on Butsumetsu (an unlucky day) 17 Accordingly, we added Taian-Butsumetsu as candidate factor affecting the length of hospital stay. The AMI case load was calculated as the average annual number of patients with AMI who were registered with the OACIS office from April 1998 to March 2003. Experience with percutaneous coronary intervention (PCI) was calculated as the average annual number of PCI procedures performed by each hospital participating in the OACIS from April 1998 to March 2003. Length of hospital stay was calculated from the date of admission to the date of discharge.

\section{Statistical Analysis}

The Mann-Whitney rank sum test was used to compare the median length of hospital stay between all variables. Because the length of hospital stay did not show a normal distribution, we used multiple regression analysis after natural logarithmic transformation of the data on hospital stay (the dependent variable) to assess factors with an independent influence on the length of hospitalization. Variables significantly associated with the length of hospital stay on univariate analysis $(\mathrm{p}<0.05)$ were entered stepwise as independent variables into the model. We also investigated trends in the length of hospital stay from April 1998 to March 2003 by one-way analysis of variance. In all analyses, significance was accepted at $\mathrm{p}<0.05$.

\section{Results}

\section{Mean Length of Hospital Stay}

The mean length of hospital stay was 31.2 days (median: 27 days) in the total study population from April 1998 to March 2003 (Fig 1).

\section{Univariate Analysis of Length of Hospital Stay}

Table 1 shows the length of hospital stay in patients with and without each of the variables. Hospital stay was longer in older patients, women, patients with diabetes mellitus, prior myocardial infarction, prior angina, and prior cerebrovascular disease, Killip $\geq 2$, systolic blood pressure $<100 \mathrm{mmHg}$, heart rate $\geq 100$ beats $/ \mathrm{min}$, and anterior myocardial infarction. It was also longer in patients who underwent emergency coronary artery bypass grafting (CABG), pulmonary artery catheterization, insertion of a temporary pacemaker, percutaneous cardiopulmonary support, intraaortic balloon pumping, mechanical ventilation, elective 
Table 2 Multiple Linear Regression Analysis of Variables Influencing Hospital Stay

\begin{tabular}{lcr}
\hline \hline Variable & Coefficient & p value \\
\hline Age & 0.111 & $<0.001$ \\
Diabetes mellitus & 0.077 & 0.003 \\
Current smoking & -0.066 & 0.017 \\
Stenting & -0.066 & 0.014 \\
Pulmonary artery catheterization & 0.057 & 0.029 \\
Temporary pacemaker & 0.056 & 0.032 \\
Percutaneous cardiopulmonary support & 0.082 & 0.003 \\
Mechanical ventilation & 0.147 & $<0.001$ \\
Coronary angiography before discharge & 0.238 & $<0.001$ \\
CABG before discharge & 0.088 & 0.001 \\
Echocardiography & 0.108 & $<0.001$ \\
Exercise testing & 0.107 & $<0.001$ \\
Thrombolytics & 0.060 & 0.024 \\
Diuretics & 0.061 & 0.036 \\
Inotropic agents & 0.081 & 0.007 \\
Congestive heart failure & 0.098 & 0.001 \\
Stroke & 0.117 & $<0.001$ \\
Bleeding & 0.126 & $<0.001$
\end{tabular}

$C A B G$, coronary artery bypass grafting.
Table 3 Multiple Linear Regression Analysis of Hospital Stay Including All Variables

\begin{tabular}{lrr}
\hline \hline Variable & Coefficient & $p$ value \\
\hline Age & 0.093 & 0.001 \\
Working & -0.068 & 0.018 \\
Diabetes mellitus & 0.064 & 0.011 \\
Prior myocardial infarction & 0.052 & 0.042 \\
Pulmonary artery catheterization & 0.109 & $<0.001$ \\
Temporary pacemaker & 0.069 & 0.007 \\
Percutaneous cardiopulmonary support & 0.078 & 0.003 \\
Mechanical ventilation & 0.139 & $<0.001$ \\
Coronary angiography before discharge & 0.258 & $<0.001$ \\
CABG before discharge & 0.101 & $<0.001$ \\
Diuretics & 0.074 & 0.008 \\
Inotropic agents & 0.062 & 0.032 \\
Congestive heart failure & 0.082 & 0.004 \\
Stroke & 0.113 & $<0.001$ \\
Bleeding & 0.119 & $<0.001$ \\
Weekend discharge & -0.065 & 0.009 \\
Performance of PCI $>$ 200 procedures/year & -0.114 & 0.034 \\
No. of beds $>200$ & -0.203 & $<0.001$ \\
AMI case load $>$ 50 patients/year & -0.123 & 0.021 \\
\hline
\end{tabular}

$A M I$, acute myocardial infarction; $C A B G$, coronary artery bypass grafting; $P C I$, percutaneous coronary intervention.

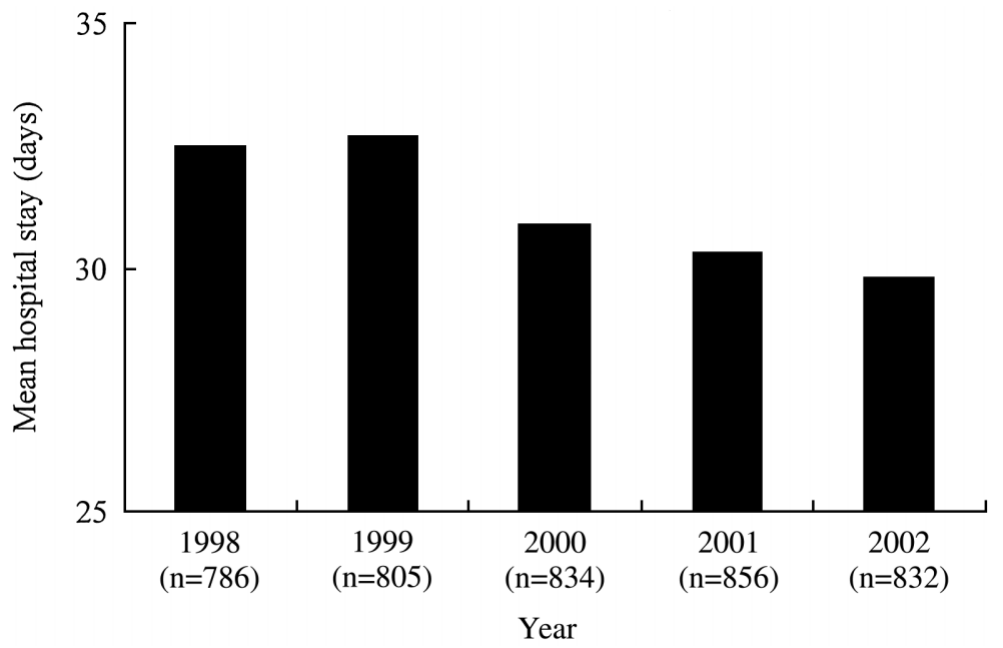

Fig 2. The trend in the mean length of hospital stay between 1998 and 2002 shows a significant decrease (one-way analysis of variance, $\mathrm{p}<0.001$ ). coronary angiography, elective PCI, elective CABG, or echocardiography. Furthermore, the hospital stay was increased in patients treated with thrombolytics, anticoagulants, diuretics, digitalis, and inotropic agents. A number of in-hospital cardiac complications were also associated with a longer stay, including congestive heart failure, cardiogenic shock, mechanical complications, reinfarction, recurrent ischemia, second- or third-degree atrioventricular block, atrial fibrillation/flutter, ventricular tachycardia/fibrillation, thromboembolism, stroke, and bleeding. Finally, the hospital stay was longer in patients discharged on Taian.

Hospital stay was shorter in working patients, obese patients, those with hyperlipidemia, and current smokers. It was also shorter when the time from onset to presentation was $<6 \mathrm{~h}$, when emergency coronary angiography was done, when coronary stenting was performed, and when patients received antiplatelet agents, angiotensin-converting enzyme inhibitors or $\beta$-blockers. Finally, it was shorter for those discharged at the weekend, and those admitted to high-volume hospitals (ie, >200 PCI procedures/year, $>200$ beds, or >50 AMI patients/year) (Table 1).

\section{Multivariate Analysis of Hospital Stay}

To evaluate the clinical factors (ie, demographic factors, coronary risk factors, medical history, infarct characteristics, procedures, medications, and in-hospital complications), apart from the day of discharge and hospital characteristics, that independently influenced the length of hospital stay, we constructed a multivariate linear regression model (Table 2). This analysis selected 18 variables as independent predictors of the length of hospital stay and the model explained $26 \%$ of the variation in hospital stay $\left(\mathrm{R}^{2}=0.26\right)$. For the full model, the day of discharge and the hospital characteristics were also added (Table 3). This analysis selected 19 variables as independent predictors of the length of hospital stay. An older age, diabetes mellitus, prior myocardial infarction, pulmonary artery catheterization, temporary pacemaker, percutaneous cardiopulmonary support, mechanical ventilation, coronary angiography before discharge, $\mathrm{CABG}$ before discharge, diuretics, inotropic agents, congestive heart failure, stroke, and bleeding were all independently associated with a longer hospital stay. In contrast, patients who were working, discharge at the weekend 
or admission to high-volume hospitals were independent predictors of a shorter hospital stay. The final model, which included all variables, explained $32 \%$ of the variation in hospital stay $\left(\mathrm{R}^{2}=0.32\right)$.

\section{Trends of Hospital Stay}

The mean length of hospital stay showed a significant decrease from 32.5 days in 1998 to 29.8 days in 2002 (Fig 2) and to evaluate the factors associated with this reduction in hospital stay we performed a multivariate linear regression analysis comparing 1998 with 2002 (Table 4). In 1998, older age, pulmonary artery catheterization, temporary pacemaker, mechanical ventilation, coronary angiography before discharge, congestive heart failure, and stroke were independently associated with a longer hospital stay and none of the factors was predictive of a shorter hospital stay. In contrast, working patients and admission to high-volume hospitals were independent predictors of a shorter hospital stay in 2002, and pulmonary artery catheterization, mechanical ventilation, coronary angiography before discharge, CABG before discharge, congestive heart failure, and bleeding were independently associated with a longer hospital stay.

\section{Discussion}

The present study revealed the following points: (1) the mean and median length of hospital stay after AMI was 31.2 days and 27 days, respectively; (2) independent predictors of a longer hospital stay were increased age, diabetes mellitus, prior myocardial infarction, pulmonary artery catheterization, insertion of a temporary pacemaker, percutaneous cardiopulmonary support, mechanical ventilation, coronary angiography before discharge, CABG before discharge, diuretics, inotropic agents, congestive heart failure, stroke, and bleeding; (3) predictors of a shorter hospital stay in 2002 were working patients, discharge on weekends, admission to a high-volume hospital; (4) the mean length of hospital stay after AMI decreased significantly from 1998 to 2002; and (5) the independent predictors of a shorter hospital stay in 2002 were not significant in 1998.

In Western countries, the mean hospital stay after AMI has steadily since the 1940s when the standard practice was at least 3-6 weeks of strict bed rest after AMI to allow time for the infarct to heal ${ }^{18,19}$ It became apparent that complete bed rest had serious physical and psychological consequences, so there was progressively earlier mobilization after $\mathrm{AMI}{ }^{20}$ until by the early 1970 s, the hospital stay after AMI had decreased to 2-3 weeks, 1,2 In the late 1970s, numerous studies using clinical criteria to define uncomplicated groups of AMI patients demonstrated that they could be discharged with a low risk as early as 7-10 days after infarction, ${ }^{1-24}$ and several randomized studies suggested the feasibility, safety, and cost effectiveness of discharging patients as early as 3-5 days after AMI3-5 Recently, the hospital stay after AMI has been reduced to approximately 7 days in Western countries, ${ }^{6-9}$ compared with 31.2 days in the present large-scale multicenter survey conducted in Japan. Although data based on large-scale surveys are insufficient in Japan, the length of hospital stay after AMI has been shown to be 3-6 weeks. ${ }^{10-14}$ In the middle of the 1990s, the length of hospital stay after AMI was 4-6 weeks $^{10,11}$ and by the late 1990 s, it was $3-4$ weeks in AMI patients treated with PCI within $12 \mathrm{~h}$ or $24 \mathrm{~h}$ after onset ${ }^{2,13}$
Table 4 Multivariate Predictors of the Length of Hospital Stay Stratified by Study Year

\begin{tabular}{lcc}
\hline \hline \multirow{2}{*}{ Variables } & \multicolumn{2}{c}{ Coefficient } \\
\cline { 2 - 3 } & 1998 & 2002 \\
\hline Age & 0.159 & \\
Working & & -0.146 \\
$\begin{array}{l}\text { Diabetes mellitus } \\
\text { Prior myocardial infarction }\end{array}$ & & \\
Pulmonary artery catheterization & 0.123 & 0.155 \\
Temporary pacemaker & 0.186 & \\
Percutaneous cardiopulmonary support & & \\
Mechanical ventilation & 0.155 & 0.271 \\
Coronary angiography before discharge & 0.159 & 0.243 \\
CABG before discharge & & 0.113 \\
$\begin{array}{l}\text { Diuretics } \\
\text { Inotropic agents }\end{array}$ Congestive heart failure & & \\
$\begin{array}{l}\text { Stroke } \\
\text { Bleeding }\end{array}$ & 0.136 & 0.213 \\
Weekend discharge & 0.171 & \\
Performance of PCI $>200$ procedures/year & & 0.118 \\
No. of beds $>200$ & & -0.227 \\
AMI case load $>50$ patients/year & & -0.236 \\
\hline
\end{tabular}

$A M I$, acute myocardial infarction; $C A B G$, coronary artery bypass grafting; $P C I$, percutaneous coronary intervention.

In the present study, the mean length of hospital stay was 29.2 days in patients treated with PCI within $12 \mathrm{~h}$ of onset and 30.5 days in those treated within $24 \mathrm{~h}$ of onset. Although the length of hospital stay seems to be longer than that in the previous studies, it is necessary to conduct a nation-wide survey to examine regional differences of the length of hospital stay after AMI. Nevertheless, the hospital stay of Japanese AMI patients seems to be extremely long and because a long hospital stay has some physical and psychological disadvantages, as well as increasing medical costs, it should reflect disease severity.

We also evaluated the factors that independently influenced the length of hospital stay after AMI. Our full model selected 19 variables as independent predictors of the length of hospital stay and it explained $32 \%$ of the variation in hospital stay. We also evaluated 18 clinical factors, excluding the discharge day and hospital characteristics, that independently influenced the length of hospital stay after AMI and these clinical variables only explained $26 \%$ of the variation in the length of hospital stay. This finding shows that the length of hospital stay did not appropriately correspond with the severity of AMI, suggesting patients could be discharged earlier without an adverse effect on the outcome. Although studies in Western countries have suggested the safety, feasibility, and cost-effectiveness of early hospital discharge after AMI,-5,25-30 it would not be reasonable to promote early discharge after AMI in Japan based solely on data from Western countries. Local randomized controlled studies are needed to examine the safety and feasibility of early discharge.

The fully adjusted model selected 14 variables as independent predictors of a longer hospital stay (Table 3) and because they all corresponded with the severity of AMI, it is reasonable that these variables were independently associated with a longer hospital stay. Furthermore, the fully adjusted model selected 5 variables as independent predictors of a shorter hospital stay (Table 3 ) and found that admission to a high-volume hospital was the important predictor of a shorter hospital stay. Although this study was 
not designed to clarify the reasons why admission to a high-volume hospital was independently associated with a shorter hospital stay, there are 2 possible explanations. First, the use of clinical pathways as standardized protocols for management of patients with AMI has been recently introduced to high-volume hospitals to improve the quality of care and reduce both costs and hospital stay. Therefore, admission to a high-volume hospital may be associated with a shorter hospital stay partly because of the use of clinical pathways, but its relatively recent introduction into the management of patients means that the design of this observational study is inappropriate to demonstrate an association between reduced hospital stay and the use of clinical pathways. Second, physicians in low-volume hospitals may be less confident with early mobilization and discharge of AMI cases, and may be more responsive to social and family pressure 6

The hospital stay decreased significantly from 32.5 days to 29.8 days during the study period. The progressive decline in the length of hospital stay may be related to the increasing use of pharmacologic and mechanical interventions to limit infarct size and recurrent ischemia, but this relationship is controversial, 7,8 so to explore factors that influenced the reduction of hospital stay after AMI during the study period, we compared independent predictors of the length of hospital stay in 1998 and 2002. In 2002, working patients and those admitted to high-volume hospitals had a shorter hospital stay, but this association was not significant in 1998. However, these results still suggest that a reduction in hospital stay may depend on employment status and admission to high-volume hospitals, which may in turn be related to recent pressures in Japan to return to work earlier and to shorten the hospital stay in high-volume hospitals. However, this conclusion is not based on the results of a randomized controlled trial in Japanese patients, but on the empirical information suggesting that a shorter stay can minimize costs without compromising the outcome. To standardize medical care, randomized controlled studies are needed to examine the safety and feasibility of early discharge after AMI in Japan.

\section{Study Limitations}

The study population consisted of patients with AMI who were admitted to collaborating hospitals in the Osaka region, so it may not reflect the characteristics of the entire Japanese population. Because it has been reported that differences in the management of AMI exist in Japan ${ }^{11}$ the length of hospital stay may differ among regions. However, the subjects registered in the study can be considered representative of the AMI population in the Osaka area, because more than one-third of all AMI patients in Osaka were registered at the participating hospitals distributed throughout the region 31 Therefore, our results may at least be generalized to the length of hospital stay after AMI and its predictors in the Osaka region.

Nearly $68 \%$ of the variation in hospital stay remains unexplained by our data. Because our study was limited by its observational design, we cannot rule out the possibility that the results were confounded by unmeasured variables. Addition of more detailed data on the socioeconomic status, social support, or discharge decisions might have provided important new variables. Further study is needed to examine whether these variables are associated with the length of hospital stay after AMI.

\section{Acknowledgements}

This work was supported by a Grant-in-Aid for Scientific Research (C) (2) (\#15590743) from the Japan Society for the Promotion of Science, Tokyo, Japan and by research funds from the Japan Arteriosclerosis Prevention Fund, Tokyo, Japan.

We thank Kumiko Miyoshi, Chizuru Hamaguchi, Hiroko Machida, Mariko Yoneda, Kana Sakatani, Nagisa Yoshioka, Miki Shinkura, Tomomi Miyai, Saeko Kakimoto, Tomoko Inoue, and Aki Yabuuchi for their excellent assistance with data collection.

\section{References}

1. Hutter AM Jr, Sidel VW, Shine KI, DeSanctis RW. Early hospital discharge after myocardial infarction. N Engl J Med 1973; 288: $1141-1144$.

2. Wenger NK, Hellerstein HK, Blackburn H, Castranova SJ. Uncomplicated myocardial infarction: Current physician practice in patient management. JAMA 1973; 224: 511-514.

3. Topol EJ, Burek K, O'Neill WW, Kewman DG, Kander NH, Shea MJ, et al. A randomized controlled trial of hospital discharge three days after myocardial infarction in the era of reperfusion. $N$ Engl $J$ Med 1988; 318: $1083-1088$.

4. Grines CL, Marsalese DL, Brodie B, Griffin J, Donohue B, Costantini $\mathrm{CR}$, et al. Safety and cost-effectiveness of early discharge after primary angioplasty in low risk patients with acute myocardial infarction. PAMI-II Investigators: Primary Angioplasty in Myocardial Infarction. J Am Coll Cardiol 1998; 31: 967-972.

5. Bogaty P, Dumont S, O'Hara GE, Boyer L, Auclair L, Jobin J, et al. Randomized trial of a noninvasive strategy to reduce hospital stay for patients with low-risk myocardial infarction. J Am Coll Cardiol 2001; 37: 1289-1296.

6. Chen E, Naylor CD. Variation in hospital length of stay for acute myocardial infarction in Ontario, Canada. Med Care 1994; 32: 420 435.

7. Every NR, Spertus J, Fihn SD, Hlatky M, Martin JS, Weaver WD. Length of hospital stay after acute myocardial infarction in the Myocardial Infarction Triage and Intervention (MITI) Project registry. J Am Coll Cardiol 1996; 28: 287-293.

8. Rogers WJ, Canto JG, Lambrew CT, Tiefenbrunn AJ, Kinkaid B, Shoultz DA, et al. Temporal trends in the treatment of over 1.5 million patients with myocardial infarction in the U.S. from 1990 through 1999: The National Registry of Myocardial Infarction 1, 2 and 3. J Am Coll Cardiol 2000; 36: 2056-2063.

9. Bartholomew BA, Harjai KJ, Grines CL, Boura JA, Grines LL, Stone GW, et al. Variation in hospital length of stay in patients with acute myocardial infarction undergoing primary angioplasty and the need to change the diagnostic-related group system. Am J Cardiol 2003; 92: 830-833.

10. Matsui K, Polanczyk CA, Gaspoz JM, Theres H, Kleber FX, Sobashima A, et al. Management of patients with acute myocardial infarction at five academic medical centers: Clinical characteristics, resource utilization, and outcome. J Investig Med 1999; 47: 134140.

11. Matsui K, Fukui T, Hira K, Sobashima A, Okamatsu S, Nobuyoshi $\mathrm{M}$, et al. Differences in management and outcomes of acute myocardial infarction among four general hospitals in Japan. Int J Cardiol 2001; 78: 277-284.

12. Fujiwara K, Hiasa Y, Takahashi T, Yamaguchi K, Ogura R, Ohara $\mathrm{Y}$, et al. Influence of diabetes mellitus on outcome in the era of primary stenting for acute myocardial infarction. Circ J 2002; 66: $800-804$.

13. Anzai H, Yoneyama S, Tsukagoshi M, Miyake T, Kikuchi T, Sakurada M. Rescue percutaneous thrombectomy system provides better angiographic coronary flow and does not increase the in-hospital cost in patients with acute myocardial infarction. Circ J 2003; 67: $768-774$.

14. Goto Y, Itoh H, Adachi H, Ueshima K, Nohara R. Use of exercise cardiac rehabilitation after acute myocardial infarction. Circ J 2003; 67: 411-415.

15. Kinjo K, Sato H, Ohnishi Y, Hishida E, Nakatani D, Mizuno H, et al. Impact of high-sensitivity $\mathrm{C}$-reactive protein on predicting long-term mortality of acute myocardial infarction. Am J Cardiol 2003; 91: 931-935.

16. Kinjo K, Sato H, Shiotani I, Kurotobi T, Ohnishi Y, Hishida E, et al. Prevalence of Helicobacter pylori infection and its link to coronary risk factors in Japanese patients with acute myocardial infarction. Circ J 2002; 66: 805-810.

17. Hira K, Fukui T, Endoh A, Rahman M, Maekawa M. Influence of superstition on the date of hospital discharge and medical cost in 
Japan: Retrospective and descriptive study. BMJ 1998; 317: 16801683.

18. Levine S. Coronary thrombosis: Its various clinical features. Medicine 1929; 8: 245.

19. Mallory G, White P, Salcedo-Salgor J. The speed of healing of myocardial infarction: A study of the pathologic anatomy in seventytwo cases. Am Heart J 1939; 18: 647.

20. Levine SA, Lown B. "Armchair" treatment of acute coronary thrombosis. J Am Med Assoc 1952; 148: 1365-1369.

21. McNeer JF, Wagner GS, Ginsburg PB, Wallace AG, McCants CB, Conley MJ, et al. Hospital discharge one week after acute myocardial infarction. N Engl J Med 1978; 298: 229-232.

22. Hill JD, Hampton JR, Mitchell JR. A randomised trial of homeversus-hospital management for patients with suspected myocardial infarction. Lancet 1978; 1: 837-841.

23. Ahlmark G, Ahlberg G, Saetre H, Haglund I, Korsgren M. A controlled study of early discharge after uncomplicated myocardial infarction. Acta Med Scand 1979; 206: 87-91.

24. Lindvall K, Erhardt LR, Lundman T, Rehnqvist N, Sjogren A. Early mobilization and discharge of patients with acute myocardial infarction: A prospective study using risk indicators and early exercise tests. Acta Med Scand 1979; 206: 169-175.

25. Sanz G, Betriu A, Oller G, Matas M, Magrina J, Pare C, et al. Feasibility of early discharge after acute $Q$ wave myocardial infarction in patients not receiving thrombolytic treatment. $J$ Am Coll Cardiol 1993; 22: 1795-1801.

26. Mark DB, Sigmon K, Topol EJ, Kereiakes DJ, Pryor DB, Candela $\mathrm{RJ}$, et al. Identification of acute myocardial infarction patients suitable for early hospital discharge after aggressive interventional therapy: Results from the Thrombolysis and Angioplasty in Acute Myocardial Infarction Registry. Circulation 1991; 83: 1186-1193.

27. Senaratne MP, Irwin ME, Shaben S, Griffiths J, Nagendran J, Kasza $\mathrm{L}$, et al. Feasibility of direct discharge from the coronary/intermediate care unit after acute myocardial infarction. J Am Coll Cardiol 1999; 33: 1040-1046.

28. Newby LK, Califf RM, Guerci A, Weaver WD, Col J, Horgan JH, et al. Early discharge in the thrombolytic era: An analysis of criteria for uncomplicated infarction from the Global Utilization of Streptokinase and t-PA for Occluded Coronary Arteries (GUSTO) trial. $J$ Am Coll Cardiol 1996; 27: 625-632.

29. Newby LK, Eisenstein EL, Califf RM, Thompson TD, Nelson CL,
Peterson ED, et al. Cost effectiveness of early discharge after uncomplicated acute myocardial infarction. $N$ Engl J Med 2000; 342: 749755.

30. van der Vlugt MJ, Boersma H, Leenders CM, Pop GA, Veerhoek MJ, Simoons ML, et al. Prospective study of early discharge after acute myocardial infarction (SHORT). Eur Heart J 2000; 21: $992-$ 999.

31. Kinjo K, Sato H, Sato H, Shiotani I, Kurotobi T, Ohnishi Y, et al. Circadian variation of the onset of acute myocardial infarction in the Osaka area, 1998-1999: Characterization of morning and nighttime peaks. Jpn Circ J 2001; 65: 617-620.

\section{Appendix 1}

The following institutions and persons participated in the OACIS.

Sakurabashi Watanabe Hospital, Osaka, Japan: Fujii K, Ito H; Osaka Police Hospital, Osaka, Japan: Kodama K, Hirayama A; Kansai Rosai Hospital, Amagasaki, Japan: Nagata S, Nanto S, Morozumi T; Osaka General Medical Center, Osaka, Japan: Fukunami M, Shimonagata T; Ishinkai Yao General Hospital, Yao, Japan: Matsu-ura Y; Osaka National Hospital, Osaka, Japan: Kusuoka H, Koretsune Y; Higashi-Osaka City General Hospital, Higashi-Osaka, Japan: Kijima Y; Osaka Rosai Hospital, Sakai, Japan: Yamada Y, Tanouchi J, Nishino M; Kawachi General Hospital, Higashi-Osaka, Japan: Mishima M, Lim YJ; Osaka Minami National Hospital, Kawachinagano, Japan: Kinoshita N, Imai K; Osaka Kosei Nenkin Hospital, Osaka, Japan: Sasaki T; Osaka Railway Hospital of West Japan Railway Company, Osaka, Japan: Ezumi A; Yao Municipal Hospital, Yao, Japan: Hoshida S, Umemoto K; Kaizuka City Hospital, Kaizuka, Japan: Morita H, Lee JM; Kita-Osaka Hospital, Osaka, Japan: Ogitani N, Otani K; Settsu Iseikai Hospital, Settsu, Japan: Akehi N; Kobe Ekisaikai Hospital, Kobe, Japan: Shimazu T, Fuji H; Kashiwara City Hospital, Kashiwara, Japan: Naka M, Akashi T; Teramoto Memorial Hospital, Kawachinagano, Japan: Hishida E; Saiseikai Senri Hospital, Suita, Japan: Hayashi T, Nakatsuchi Y; Meiwa Hospital, Nishinomiya, Japan: Sugii M; Osaka Kaisei Hospital, Osaka, Japan: Kawabata M; Osaka Seamens Insurance Hospital, Osaka, Japan: Kohama A; Department of Internal Medicine and Therapeutics, Osaka University Graduate School of Medicine, Suita, Japan: Otsu K, Yamamoto K; Department of Medical Information Science, Osaka University Graduate School of Medicine, Suita, Japan: Takeda H, Matsumura Y. 